\title{
EDITORIAL
}

\section{Air pollution effects in the elderly: introduction}

\author{
M. Decramer*, R. Loddenkemper", J. Boe ${ }^{\uparrow}$, J. Roca ${ }^{+}$, M. Zelter ${ }^{\S}$
}

At the 1998 European Respiratory Society (ERS) Congress in Geneva, M. Decramer (at the time Chairman of the Scientific Programme Committee) and R. Loddenkemper (President) had the idea to follow a new avenue in the activity of the Society: i.e. to foster the participation of the European respirologists in the research activity funded by the European Union.

They asked A. Davies, an experienced British retired professor of molecular biology, to be the ERS consultant for the European Union (EU)-related activities, and gathered a bunch of ERS members. Among them, G. Viegi (a respiratory epidemiologist, newly elected Head of the Occupation and Epidemiology Assembly) and T. Sandström (a pulmonary physician and basic scientist, member of the Occupational and Environmental Health Working Group) were invited to submit a project on air pollution effects. They identified the elderly (i.e. $\geqslant 65 \mathrm{yrs}$ ) as a segment of the general population which might be particularly vulnerable to the effects of air pollution and for whom there was lack of knowledge, according to the MEDLINE search.

G. Viegi and T. Sandström prepared, with the invaluable assistance of $\mathrm{T}$. Davies, a proposal which was submitted to the EU in October 1999, approved in April 2000 and the contract started to be effective in October 2000.

The proposal concerned holding a conference as an accompanying measure to Key Action 4, Environment and Health, of the Quality of Life work program. A small multidisciplinary group of European scientists were proposed to meet to focus on the influence of environmental factors on the elderly with emphasis on respiratory disease. Particular attention would be paid to the health effects of photochemical mixtures, particulate matter and atmospheric acidity, the effects of long-term exposure in relation to the development of chronic obstructive pulmonary disease (COPD) and asthma and the effects of peak exposure in special meteorological and topographical circumstances. The outcome would be the production of authoritative written statements on the topic of discussion and possibly the subsequent preparation of a research proposal to a proper EU call.

A workshop on "Air Pollution Effects in the Elderly" was held in Pisa, March 12-14 2001. There were 28 presentations, each followed by a thorough interdisciplinary discussion.

There was an epidemiological overview on prevalence, incidence and healthcare costs of COPD and asthma, as well as on risk factors which might be effect modifiers or confounders, such as chronic mucus hypersecretion, active and

*Respiratory division, University Hospital, Katholieke Universiteit Leuven, Leuven, Belgium, " Lungenklinik Heckeshorn, Berlin, Germany, "Dept of Thoracic Medicine, Rikshospitalet, University of Oslo, Oslo, Norway, ${ }^{+}$Servei Pneumologia, Hospital Clinic, Barcelona, Spain, ${ }^{8}$ Hospital Pitie Salpetriere, Laboratoire de Physiologie, Paris, France.

Correspondence: M. Decramer, Respiratory Division, University Hospital, Herestraat 49, B-3000 Leuven, Belgium. Fax: 3216346803. E-mail: Marc.Decramer@uz.kuleuven.ac.be passive smoking, occupational exposures, indoor pollution, respiratory infections and cardiovascular comorbidity.

As tools of respiratory investigation, questionnaires and lung function assessment (mainly spirometry and peak expiratory flow monitoring) were overviewed.

Many atmospheric pollutants were considered, mainly gases such as carbon monoxide, nitrogen dioxide, sulphur dioxide, and ozone, as well as various airborne particles of complex composition and widely differing size (PM10 and PM2.5 (particles with a 50\% cut-off aerodynamic diameter of $10 \mu \mathrm{m}$ and $2.5 \mu \mathrm{m}$, respectively)) and ultrafine particles with an upper size limit of 100 nanometres (i.e. $0.1 \mu \mathrm{m}, \mathrm{PM} 0.1$ ).

The workshop was an occasion for the presentation of preliminary results on ambient particle concentrations and mortality among elderly from the APHEA2 project, which is the second phase of an EU project, APHEA (Air Pollution and Health: a European Approach).

Another contribution on air pollution and mortality came from the Netherlands, whilst from the UK a study was presented on air pollution and daily admissions to hospital for cardiorespiratory diseases.

The issue of susceptibility or frailty of the elderly was covered with presentations on the effect of components of air pollution on the bronchial mucosa, on genetic differences in susceptibility, on what subpopulations are at increased risk of adverse health outcomes from air pollution? An EU funded collaborative project ("Health Effects of Air Pollution on Susceptible Subpopulations: Ultrafine Particles and Myocardial Infarction", HEAPSS), currently under way, was mentioned.

Lastly, reversibility of adverse chronic respiratory health effects, so far in children, was examined in a study carried out in East Germany over a particular period of 7 yrs during which the air pollution profile was significantly reduced.

Mechanisms of air pollution effects were addressed though presentations on animal models of susceptibility and their utility in studies of air pollution, oxidant/antioxidant issues worth considering, changes in heart rate variability in young and elderly humans exposed to concentrated ambient air particles, and mechanisms of adverse effects caused by ultrafine particles.

The abstracts of the presentations [1] were distributed to the members of Assembly 6.0 "Occupation and Epidemiology", as well as to the Executive Committee members.

The presence at the conference of $\mathrm{T}$. Davies allowed the content of the presentations and the recommendations to be encapsulated in a shorter lay intelligible document which was offered to the Commission of the European Community and was installed on the ERS website on November 2001 [2].

Meanwhile, the ERS Executive Committee had asked the Editor of the European Respiratory Journal (ERJ) to host the publication of the proceedings of the conference in a Supplement of the ERJ in view of the interest of air pollution for the readership and for the sake of visibility of the ERS as a clinical scientific society also devoted to a public health agenda. 
The 28 presenters were asked, when possible, to combine their topics in the effort to assemble a reduced number of coherent papers. After a first editorial work by G. Viegi and T. Sandström, the 16 manuscripts were submitted to the Supplement Editor (R. Rodriguez-Roisin, former ERS President) by late spring 2002. The editorial activity has then been completed by September 2002.

Thus, the AFORDEE (in Anticipation of Focus On Respiratory Disease in the European Elderly) initiative has encompassed the life of the ERS during the mandate of four Presidents, who have been asked to collaborate to write this Introduction.

The interest of the ERJ in air pollution is proven by the number of papers on this topic published in the last 4 yrs. A MEDLINE search from September 1998 to August 2002, using the keywords "air pollution" and "Eur Respir $J$ " has given 59 publications.

The recent publications by KUnZLi [3] and D'AMATO et al. [4], as part of the series "Contributions from the European Respiratory Monograph", are the most recent demonstrations of the paramount role of air pollution in inducing and exacerbating respiratory diseases, as well as of the huge public health gain obtainable from a preventive policy.

With this current Supplement, the ERJ and the ERS are confirmed as European front-runners in the research on air pollution effects in humans.
The Sixth Framework Programme of the European Union will be the occasion to profoundly deepen the knowledge on air pollution effects in humans through studies on issues pointed out in the AFORDEE initiative, such as longitudinal studies of lung function testing in the elderly, genetic response to inflammatory agents, severe asthma, interaction between air pollutants, comorbidity, indoor environments, role of oxidative stress in exacerbation of chronic lung disease, ultrafine particles, and vaccination of the elderly against both influenza and pneumococci.

\section{References}

1. Viegi G, Sandström T. Air pollution effects in the elderly. Abstract book of the workshop held in Pisa (Italy), March 12-14, 2001. Pisa, CNR.

2. Davies AJS. Summary report of the workshop "Air pollution effects in the elderly" held in Pisa (Italy), March 12-14, 2001; www.ersnet.org. Date accessed: December 9, 2002.

3. Kunzli K. The public health relevance of air pollution abatement. Eur Respir J 2002; 20: 198-209.

4. D'Amato G, Liccardi G, D'Amato M, Cazzola M. Outdoor air pollution, climatic changes and allergic bronchial asthma. Eur Respir J 2002; 20: 763-776. 